\title{
The maternal and perinatal outcome in antepartum hemorrhage: A cross-sectional study
}

\begin{abstract}
Background and Objective: Antepartum hemorrhage is one of the major causes of obstetric hemorrhage and contributes to significant maternal and perinatal morbidity and mortality especially in developing countries with low resources and facilities. This study aimed to determine the incidence, to estimate maternal and perinatal outcome in relation to the types of antepartum hemorrhage, and to find out factors affecting the perinatal outcome.

Methods: This cross-sectional study was carried out from February $1^{\text {st }}$ to August $1^{\text {st }}, 2016$, at the Maternity Teaching Hospital, Erbil city, Kurdistan region, Iraq. The study included 343 pregnant ladies presented with antepartum hemorrhage after 28 weeks gestation.

Results: The incidence of antepartum hemorrhagein our study was $2.34 \%$. Placenta previa was the commonest type of antepartum hemorrhage $58 \%$, followed by abruption placenta $36.7 \%$. Placenta previa was most commonly occurred in women with previous caesarean scar $(91 \%)$ and those with previous curettage $(77 \%)$, while abruptio placentae was most commonly associated with preeclampsia $(72.9 \%)$, previous antepartum hemorrhage $(66.7 \%)$ and parity $\geq 5(51.2 \%)$, Most cases of placenta previa $(94.4 \%)$ delivered by caesarean section while this figure was $57.1 \%$ for abruption. Perinatal mortality in our study was $23.64 \%$. Increasing birth weight and cesarean delivery were significantly associated with lower perinatal mortality.

Conclusion: Antepartum hemorrhage was associated with high maternal and perinatal mortality and morbidity. Placenta previa most commonly developed in women with previous uterine surgeries. In contrast, abruptio placentae developed mostly in grand multiparous women and those with preeclampsia. Most perinatal deaths occurred in babies with small gestational ages( $<34$ weeks), low birth weight babies $(<2.5 \mathrm{~kg})$, and those who delivered vaginally.
\end{abstract}

Keywords: Antepartum hemorrhage; abruption placentae; maternal and perinatal outcome; and placenta previa.

\section{Introduction}

Antepartum hemorrhage (APH) is an emergency obstetrical condition that accounts for $2-5 \%$ of pregnancies and contributes to a high level of maternal and perinatal mortality and morbidity. ${ }^{1}$ It was responsible for 4 maternal deaths in the UK Confidential Enquiries in to Maternal Deaths at 2006 -2008 report, in which hemorrhage was accounting for the sixth highest direct cause of maternal death, ${ }^{2}$ On the other hand 108 maternal deaths attributed to APH in the 2005-2007 report of the Confidential Enquiries in to Maternal Deaths in South Africa, of which 68.5\% were found to be clearly avoidable. ${ }^{3} \mathrm{APH}$ is defined as any bleeding from the genital tract that occurs between 24 weeks of gestation and delivery of the baby. The two major attributes of APH are placenta previa and abruptio placentae whereas other causes are local causes and unexplained $\mathrm{APH}$ (which is defined as failure to identify a cause for APH). ${ }^{4}$ Maternal consequences of antepartum hemorrhage are grave and include shock, postpartum hemorrhage,

* Department of Obstetrics and Gynecology, College of Medicine, Hawler Medical University, Erbil, Iraq. 
coagulation failure, preterm labor and increased rate of cesarean section. ${ }^{5}$ Further, prolonged hospitalization due to sepsis and renal failure contributes to extra financial burden, and studies reported $1 \%$ to $4.5 \%$ rate of intensive care unit admission. ${ }^{6,7}$ Although analyzing various risk factors like previous placental abruption, pre-eclampsia. Multiparity and nonvertex presentation are important in predicting abruptio placenta, APH remains largely unpredictable and has heterogeneous pathophysiology. ${ }^{8}$ On the other hand, an increase in the rate of cesarean section in modern obstetrics has a role in increasing incidence of placenta previa with an increased risk of morbidly adherent placentae. ${ }^{9}$ Antepartum hemorrhage is regarded an important obstetric cause of perinatal mortality and morbidities like prematurity, birth asphyxia, and low birth weight. The frequency of such complications will increase when the hemorrhage is heavy or the baby delivered at early gestations ${ }^{10}$ Evidence shows that improved obstetrical care has an important role in better outcomes of APH, as studies revealed that maternal and newborn outcome of APH differ greatly between developing and developed countries. ${ }^{11}$ The current study aimed to determine the incidence, associated factors, and the degree of maternal and perinatal complications of $\mathrm{APH}$ in Maternity Teaching Hospital.

\section{Methods}

Spending at least six months from February 1/ 2016 to August 1/ 2016, this study was a cross-sectional study carried out on 343 women with APH in the Maternity Teaching Hospital, a tertiary care referral hospital, where all the referral cases from the countryside hospitals are received. Included criteria were all pregnant ladies with the diagnosis of APH after 28 weeks gestation that presented as vaginal bleeding to emergency labor ward. Patients accidentally diagnosed by ultrasound to have placenta previa who admitted for elective cesarean section also included in the study. After admission and resuscitative measures, if needed, verbal informed consent is to be obtained. Sociodemographic characters like age, occupation, and parity were noted. Women classified into those who never born a child and they were in their first pregnancy, described as nulliparous women, while multiparous women (Para1-4) are those with a history of 1-4 deliveries, and Para $\geq 5$ described as grand multiparity. Inquiry about booking status, which is the history of previous antenatal visits in this pregnancy were done. Gestational age was calculated from early ultrasound or by using Naegeles rule for those who have no ultrasound. Meanwhile, other important parameters such as the cause of $\mathrm{APH}$ and associated risk factors are also recorded, and the causes of $\mathrm{APH}$ are divided into placenta previa, abruption placentiae, and unexplained causes. Notably, complete physical examination, obstetrical ultrasound, and relevant investigations according to hospital policy are performed for all patients. Mothers and babies were followed up until one week after birth, and for those who discharged earlier tracing done by contact through phone numbe rs, during the period of follow up the mode of delivery, information's regarding maternal complications like shock, required blood transfusion, postpartum hemorrhage, peripartum hysterectomy, and maternal death were recorded. Neonatal outcome including weight, gender, maturity, admissions to the nursery, and perinatal mortality, which is the death of the baby at any time from 28 weeks gestation until seven days post-delivery, were analyzed.

\section{Ethical approval}

The Research Ethics Committee of Hawler Medical University approved the study proposal. Informed verbal consent was taken from each participant of the study.

\section{Statistical methods and data analysis}

Data were analyzed using the Statistical Package of Social Sciences (SPSS) v 18. Chi-Square test was used to analyze 
associations between type of $\mathrm{APH}$ and different variables like demographical variables, obstetrical conditions, maternal and perinatal complications. Logistic regression was performed to ascertain the effects of weight, mode of delivery, APH types and shock on the likelihood of perinatal mortality. A $P$ value $\leq 0.05$ was considered statistically significant.

\section{Results}

Out of 14609 deliveries at Maternity Teaching Hospital, 343 cases were presented with $\mathrm{APH}$. Eight of them were twins. Consequently, the total numbers of babies delivered were 351 babies. The incidence of $\mathrm{APH}$ was $2.34 \%$, of which $36.7 \%$ of underlying causes were due to abruption placentae, and $58 \%$ due to placenta previa considering that among placenta previa 14 ladies were previa accreta. Table 1 shows the association of maternal demography with types of antepartum hemorrhage. On the one hand,
It is found out that $54.1 \%$ of women aged $\leq 20$ years developed abruption placentae compared with $34.5 \%$ and $35.3 \%$ among women aged $21-34$ years and $\geq 35$ years respectively. On the other hand, women aged 21-34 years were the most common presenting ages in placenta previa group $(60.1 \%)$. It is to be stated that there was no significant association between maternal ages and booking status with different types of APH while significant association was found between types of APH with both gestational age (GA) and parity, $62.2 \%$ of the nulliparous women developed abruptio placentae compared with $30 \%$ among multiparous women (Para1-4), while 64.2\% of multiparous women developed placenta previa. Women with GA $<34$ weeks, commonly presented with abruption placentae comparing to women with GA between 34-36 weeks and $\geq 37$ weeks in which placenta previa were most common (62.8\% and $62 \%$, respectively).

Table 1: Association of maternal demography with antepartum hemorrhage types.

Antepartum haemorrhage Types

\begin{tabular}{|c|c|c|c|c|c|c|c|c|c|}
\hline \multirow[t]{2}{*}{ Categories } & & \multicolumn{2}{|c|}{$\begin{array}{l}\text { Abruptio Placentae } \\
\qquad N=126\end{array}$} & \multicolumn{2}{|c|}{$\begin{array}{l}\text { Placenta Previa } \\
\qquad N=199\end{array}$} & \multicolumn{2}{|c|}{$\begin{array}{l}\text { Undetermined } \\
\qquad \mathrm{N}=18\end{array}$} & \multirow{2}{*}{$\begin{array}{l}\text { Total } \\
\text { No. }\end{array}$} & \multirow[t]{2}{*}{$P$ value } \\
\hline & & No. & $\%$ & No. & $\%$ & No. & $\%$ & & \\
\hline \multirow[t]{3}{*}{ Age } & $\leq 20$ & 20 & 54.1 & 16 & 43.2 & 1 & 2.7 & 37 & \multirow{3}{*}{0.240} \\
\hline & $21-34$ & 82 & 34.5 & 143 & 60.1 & 13 & 5.5 & 238 & \\
\hline & $\geq 35$ & 24 & 35.3 & 40 & 58.8 & 4 & 5.9 & 68 & \\
\hline \multirow[t]{3}{*}{ Parity } & Nulliparous & 28 & 62.2 & 16 & 35.6 & 1 & 2.2 & 45 & \multirow{3}{*}{$<0.001$} \\
\hline & Para1-4 & 77 & 30.0 & 165 & 64.2 & 15 & 5.8 & 257 & \\
\hline & Para $\geq 5$ & 21 & 51.2 & 18 & 43.9 & 2 & 4.9 & 41 & \\
\hline \multirow[t]{2}{*}{ Booking status } & Unbooked & 80 & 38.3 & 118 & 56.5 & 11 & 5.3 & 209 & \multirow[b]{2}{*}{0.752} \\
\hline & Booked & 46 & 34.3 & 81 & 60.4 & 7 & 5.2 & 134 & \\
\hline \multirow[t]{3}{*}{$\mathrm{GA}^{*}$} & $<34$ & 44 & 56.4 & 34 & 43.6 & 0 & 0 & 78 & \multirow{3}{*}{$<0.001$} \\
\hline & $34-36$ & 30 & 34.9 & 54 & 62.8 & 2 & 2.3 & 86 & \\
\hline & $\geq 37$ & 52 & 29.1 & 111 & 62.0 & 16 & 8.9 & 179 & \\
\hline \multirow[t]{2}{*}{ Occupation } & Housewife & 108 & 38.4 & 159 & 56.6 & 14 & 5.0 & 281 & \multirow[b]{2}{*}{0.371} \\
\hline & Employed & 18 & 29.0 & 40 & 64.5 & 4 & 6.5 & 62 & \\
\hline
\end{tabular}

${ }^{*} \mathrm{GA}$ : Gestational age. 
Table 2 shows the associated obstetrical condition with the types of $\mathrm{APH}$, and it points out that placenta previa was mostly occurred in anemic women (57.8\%), women with previous caesarean scar $(91 \%)$ and those with previous curettage $(77.0 \%)$, but with significant association between them. Meanwhile, abruption placentae mostly occurred among those with preeclampsia $(72.9 \%)$, previous $\mathrm{APH}$ $(66.7 \%)$ and parity $\geq 5(51.2 \%)$, again with a significant association between them. Table 3 shows the incidence of maternal complications by type of APH, $94.4 \%$ of women with placenta previa delivered by cesarean section. This figure was $57.1 \%$ in abruption placentae, which is statistically significant. There were three cesarean hysterectomy cases in our study, all of them were for previa accreta trying to stop bleeding, one of them ended with maternal death due to irreversible shock.

Table 2: Association of obstetrical conditions with antepartum hemorrhage types.

\begin{tabular}{|c|c|c|c|c|c|c|c|c|}
\hline \multirow{3}{*}{$\begin{array}{l}\text { Obstetrical } \\
\text { conditions }\end{array}$} & \multicolumn{7}{|c|}{ Antepartum haemorhage(APH) Types } & \multirow{3}{*}{$P$ value } \\
\hline & \multicolumn{2}{|c|}{ Abruptio Placentae } & \multicolumn{2}{|c|}{ Placentaprevia } & \multicolumn{2}{|c|}{ Undetermined Cause } & \multirow{2}{*}{$\begin{array}{l}\text { Total } \\
\text { No. }\end{array}$} & \\
\hline & No. & $\%$ & No. & $\%$ & No. & $\%$ & & \\
\hline Anemia & 120 & 38.1 & 182 & 57.8 & 13 & 4.1 & 315 & 0.004 \\
\hline Preeclampsia & 35 & 72.9 & 12 & 25.0 & 1 & 2.1 & 48 & $<0.001$ \\
\hline Previous APH & 12 & 66.7 & 5 & 27.8 & 1 & 5.6 & 18 & 0.022 \\
\hline Malpresentation & 15 & 28.8 & 34 & 65.4 & 3 & 5.8 & 52 & 0.440 \\
\hline Multiple pregnancy & 6 & 75.0 & 2 & 25.0 & 0 & .0 & 8 & 0.073 \\
\hline Previous scar & 10 & 8.13 & 112 & 91.0 & 1 & 0.81 & 123 & $<0.001$ \\
\hline Previous curettage & 13 & 21.3 & 47 & 77.0 & 1 & 1.6 & 61 & 0.004 \\
\hline Parity $\geq 5$ & 21 & 51.2 & 18 & 43.9 & 2 & 4.9 & 41 & $<0.001$ \\
\hline
\end{tabular}

Table 3: Incidence of maternal complications by types of antepartum hemorrhage.

\begin{tabular}{|c|c|c|c|c|c|c|c|}
\hline \multirow{2}{*}{ Complications } & \multicolumn{2}{|c|}{$\begin{array}{c}\text { Abruptio Placentae } \\
\text { N=126 Cases }\end{array}$} & \multicolumn{2}{|c|}{$\begin{array}{c}\text { Placentaprevia } \\
\text { N=199 Cases }\end{array}$} & \multicolumn{2}{|c|}{$\begin{array}{c}\text { Undetermined Cause } \\
\text { N=18 Cases }\end{array}$} & \multirow{2}{*}{$P$ value } \\
\hline & No. & $\%$ & No. & $\%$ & No. & $\%$ & \\
\hline Blood Units $\geq 5$ & 7 & 5.55 & 10 & 5.02 & 0 & .0 & 0.008 \\
\hline Postpartum hemorrhage & 14 & 11.1 & 24 & 12.0 & 1 & 5.55 & 0.702 \\
\hline Shock & 19 & 15.0 & 17 & 8.54 & 0 & .0 & 0.057 \\
\hline Cesarean section & 72 & 57.1 & 188 & 94.4 & 9 & 50.0 & \\
\hline Caesarian Hysterectomy & 0 & .0 & 3 & 1.50 & 0 & .0 & $<0.001$ \\
\hline Maternal death & 0 & .0 & 1 & 0.50 & 0 & .0 & 0.696 \\
\hline
\end{tabular}


Table 4 shows the incidence of perinatal complication by types of $\mathrm{APH}$, low birth weight (LBW) and premature babies were found to be common in both abruption placentae and placenta previa than undetermined causes, the perinatal mortality was the commonest in placental abruption $(36.3 \%)$ while in placenta previa were $(17.4 \%)$, and $(0 \%)$ in undetermined causes, which are also statistically significant. The rate of perinatal mortality (PNM) in our study was $23.64 \%$. Table 5 shows that statistically significant associations were found between PNM and birth weight. It was found that babies weighing $<1.5 \mathrm{~kg}$ and $>2.5 \mathrm{~kg}$ were most commonly developed stillbirth $(62.16 \%$ and $75 \%$, respectively) while babies weighing between 1.5-2.5 $\mathrm{kg}$, most commonly developed early neonatal death $(64.29 \%)$. On the other hand, babies with GA $<34$ weeks most commonly developed stillbirth $(52.63 \%)$, compared to babies with GA between $34-36$ weeks and $\geq 37$ weeks which were $(42.86 \%)$ and $(41.65 \%)$ respectively while babies with GA between 34-36 weeks and $\geq 37$ weeks were most commonly developed early neonatal death $(57.14 \%$ and $58.33 \%$, respectively). Furthermore, vaginally delivered babies were most commonly stillborn $(90 \%)$ while babies born by cesarean section mostly developed early neonatal death $(73.08 \%)$. Additionally, those women who presented with abruption placentae and those who presented with shock were most commonly had stillbirth babies, while women with placenta previa and those women presented without shock mostly had early neonatal death, which was statistically significant. Logistic regression was performed to ascertain the effects of weight, mode of delivery, and shock on the likelihood of PNM. The shock was 9.6 times more likely to exhibit PNM than those without shock. Increasing the weight of the baby was significantly associated with a reduction in the likelihood of PNM. Cesarean section and cesarean hysterectomy, represented as the mode of delivery, are significantly associated with decreasing in the likelihood of PNM, Table 6.

Table 4: Incidence of perinatal complication by types of antepartum hemorrhage.

\begin{tabular}{|c|c|c|c|c|c|c|c|}
\hline \multirow{2}{*}{ Complications } & \multicolumn{2}{|c|}{$\begin{array}{l}\text { Abruptio Placentae } \\
\quad \mathrm{N}=132\end{array}$} & \multicolumn{2}{|c|}{$\begin{array}{l}\text { Placentaprevia } \\
\quad \mathrm{N}=\mathbf{2 0 1}\end{array}$} & \multicolumn{2}{|c|}{$\begin{array}{c}\text { Undetermined Cause } \\
\text { N=18 Cases }\end{array}$} & \multirow{2}{*}{$P$ value } \\
\hline & No. & $\%$ & No. & $\%$ & No. & $\%$ & \\
\hline Perinatal mortality & 48 & 36.3 & 35 & 17.4 & 0 & 0 & $<0.001$ \\
\hline Admission to nursery & 62 & 46.9 & 81 & 40.2 & 4 & 22.2 & 0.085 \\
\hline LBW $^{*}$ & 67 & 50.7 & 69 & 34.3 & 1 & 5.55 & $<0.001$ \\
\hline $\mathrm{GA}^{*}<37$ Weeks & 74 & 56.0 & 88 & 43.7 & 2 & 11.1 & $<0.001$ \\
\hline $\begin{array}{l}\text { *LBW: Low birth weight } \\
{ }^{*} \text { GA: gestational age }\end{array}$ & & & & & & & \\
\hline
\end{tabular}


Table 5: Association of maternal and fetal outcome with perinatal mortality.

\begin{tabular}{|c|c|c|c|c|c|c|c|c|}
\hline \multirow{2}{*}{\multicolumn{2}{|c|}{ Fetal \& maternal outcomes }} & \multicolumn{6}{|c|}{ Perinatal mortality } & \multirow{3}{*}{$P$ value } \\
\hline & & \multicolumn{2}{|c|}{ Stillbirth } & \multicolumn{2}{|c|}{$\begin{array}{l}\text { Early neonatal } \\
\text { death }\end{array}$} & \multicolumn{2}{|c|}{ Total } & \\
\hline & & No. & $\%$ & No. & $\%$ & No. & $\%$ & \\
\hline \multirow[t]{3}{*}{ Weight } & $<1.5 \mathrm{~kg}$ & 23 & 62.16 & 14 & 37.84 & 37 & 100 & \multirow{3}{*}{$<0.001$} \\
\hline & $1.5-2.5 \mathrm{~kg}$ & 15 & 35.71 & 27 & 64.29 & 42 & 100 & \\
\hline & $>2.5$ & 3 & 75.00 & 1 & 25.00 & 4 & 100 & \\
\hline \multirow[t]{3}{*}{$\mathrm{GA}^{*}$} & $<34$ & 30 & 52.63 & 27 & 47.37 & 57 & 100 & \multirow{3}{*}{$<0.001$} \\
\hline & $34-36$ & 6 & 42.86 & 8 & 57.14 & 14 & 100 & \\
\hline & $\geq 37$ & 5 & 41.67 & 7 & 58.33 & 12 & 100 & \\
\hline \multirow[t]{2}{*}{ Gender } & Male & 21 & 41.18 & 30 & 58.82 & 51 & 100 & \multirow[b]{2}{*}{0.151} \\
\hline & Female & 20 & 62.50 & 12 & 37.50 & 32 & 100 & \\
\hline \multirow{3}{*}{$\begin{array}{l}\text { Mode of } \\
\text { delivery }\end{array}$} & Vaginal & 27 & 90.00 & 3 & 10.00 & 30 & 100 & \multirow{3}{*}{$<0.001$} \\
\hline & Cesarean section & 14 & 26.92 & 38 & 73.08 & 52 & 100 & \\
\hline & Cesarian Hysterectomy & 0 & 0.00 & 1 & 100.00 & 1 & 100 & \\
\hline \multirow[t]{3}{*}{ APH $^{*}$ Types } & Abruptio Placentae & 30 & 62.50 & 18 & 37.50 & 48 & 100 & \multirow{3}{*}{$<0.001$} \\
\hline & Placentaprevia & 11 & 31.43 & 24 & 68.57 & 35 & 100 & \\
\hline & Undetermined Cause & 0 & 0.00 & 0 & 0.00 & 0 & 100 & \\
\hline \multirow[t]{2}{*}{ Shock } & No & 25 & 39.06 & 39 & 60.94 & 64 & 100 & \multirow[b]{2}{*}{$<0.001$} \\
\hline & Yes & 16 & 84.21 & 3 & 15.79 & 19 & 100 & \\
\hline \multicolumn{2}{|l|}{ Total } & 41 & 49.40 & 42 & 50.60 & 83 & 100 & \\
\hline
\end{tabular}

${ }^{*} \mathrm{GA}$ : Gestational birth

${ }^{*} \mathrm{APH}$ : Antepartum hemorrhage

Table 6: Model of logistic regression where the dependent variable is perinatal mortality.

\begin{tabular}{|c|c|c|c|c|c|}
\hline \multirow{2}{*}{ Independent variables } & \multirow{2}{*}{ B } & \multirow{2}{*}{$P$ value } & \multirow{2}{*}{ OR } & \multicolumn{2}{|c|}{ 95\% C.I. for OR } \\
\hline & & & & Lower & Upper \\
\hline $\begin{array}{l}\text { Shock } \\
\text { Reference: shock (not present), }\end{array}$ & 2.263 & $<0.001$ & 9.612 & 3.072 & 30.073 \\
\hline $\begin{array}{l}\text { Weight of baby }>2.5 \mathrm{~kg} \\
\text { Reference: weight of baby }(<2.5 \mathrm{~kg}) \text {, }\end{array}$ & -3.621 & $<0.001$ & 0.027 & 0.011 & 0.067 \\
\hline $\begin{array}{l}\text { Mode of Delivery (CS* \& Caesarean } \\
\text { hysterectomy) } \\
\text { Reference: Mode of delivery (vaginal) }\end{array}$ & -1.237 & 0.002 & 0.290 & 0.133 & 0.635 \\
\hline Constant & -17.714 & 0.998 & 0.000 & & \\
\hline
\end{tabular}




\section{Discussion}

The incidence of APH in Maternity Teaching Hospital within a six months period in our study was $2.34 \%$. This was close to the incidence reported by Majumder et al. ${ }^{12}$ which was $3.8 \%$ and in Wasnik et al ${ }^{13}$ was $1.3 \%$. Nevertheless, this may not reflect the true incidence because this hospital is the only tertiary hospital that will accept all high risk pregnancies referred to from other hospitals and the peripheral hospitals. Likewise, APH cases with mild bleeding are managed in private hospitals. Placenta previa was the commonest cause of $\mathrm{APH}$ in our study $58 \%$, followed by abruptio placentae $36.7 \%$, this finding was parallel to Jejani Ayushma et al. ${ }^{14}$ and Wasnik et al., ${ }^{13}$ while Kedar et $a^{15}$ found abruptio placentae more common than placenta previa, $51.9 \%$, and $45.80 \%$ respectively. This difference may go to the fact that our study also included elective cases of placenta previa that diagnosed accidentally by ultrasound. In the present study, $60.9 \%$ of APH women were unbooked, $38.3 \%$ of unbooked $\mathrm{APH}$ women was in the abruptio placentae group while $56.5 \%$ in the placenta previa group, Kedar et al ${ }^{15}$ study found $69.11 \%$ of abruption placenta and $60 \%$ of placenta previa were unbooked. Majumder et al. ${ }^{12}$ also found that most APH cases were unregistered (64\%) in his study. Further, our study found that ladies representing 21-34 years age group is the commonest age group for $\mathrm{APH}$, and most of them were multiparous, and housewife. This was consistent with Majumder et al. ${ }^{12}$ and Archana Maurya et al. ${ }^{16}$ studies. In our study, the gestational age at delivery was commonly below 37 weeks gestation in abruptio placentae group, while in placenta previa, most women 111 (62\%) were 37 weeks or more. Kedar et al. ${ }^{15}$ study found most abruptio placentae and placenta previa women presented at term, 60.29\% and $56.67 \%$ respectively, but Majumder et al. ${ }^{12}$ found placenta previa mostly occurred between 33-36 weeks gestation (47\%) and abruptio placenta mostly developed at term
$(15 \%)$. This may be because our study also included elective cases of placenta previa in which cesarean section arranged for them at or more than 37 weeks of gestation. Preeclampsia was commonest in abruption placentae: 35 cases (72.9\%) followed by $12(25 \%)$ in placenta previa, and this was in agreement with Majumder $S$ et $\mathrm{al}^{12}$ in which preeclampsia associated with 18 cases of abruption placentae versus 4 cases of placenta previa. In Kedar et $\mathrm{al}^{15}$ study these figures were 36 $(52.94 \%)$ and $3(5 \%)$ respectively. It is also consistent to Singh AG et al. ${ }^{17}$ study which found preeclampsia associated with $56.86 \%$ of abruption placentae. Anemia was found to be an important risk factor for all types of $\mathrm{APH}$. It is found in $91.8 \%$ of women, this is identical to Jejani Ayushma et al. ${ }^{14}$ which was $71.9 \%$, and in S Singhal study $^{18}$ was $100 \%$. Placenta previa mostly occurred in anemic women 182 (57.8\%) in our study, which was consistent with Majumder $S$ et al. $^{12}$ who found most women with placenta previa were anemic. Our study showed a strong association of uterine surgeries with APH especially in placenta previa group, for instance, 91\% of a previous scar and $77 \%$ of the previous curettage found in association with placenta previa group. Kedar et al. ${ }^{15}$ in his study also found placenta previa significantly occurred in previous scawomen, $41.6767 \%$ and women with the previous curettage $11.67 \%$. In the current study most of malpresented fetuses were found in association of placenta previa 34 cases $(65.4 \%)$ compared to 15 cases $(28.8 \%)$ of abruption placentae women, which was consistent with both Majumder et al. ${ }^{12}$ and Arora et al. ${ }^{19}$ studies, whom they found in their studies that malpresentation was more commonly observed in women with placenta previa than women with abruption placentae.In present study caesarean section was the commonest mode of delivery in placenta previa done for 188 cases (94.4\%) in compared to 72 cases $(57.1 \%)$ of abruption placentae, and this was consistent with 
Kedar et al. ${ }^{15}$ study which reported $93.33 \%$ of placenta previa delivered by caesarean section versus $44.11 \%$ in abruption placentae. Nega Chufamo ${ }^{20}$ also found cesarean section was the commonest mode of delivery in placenta previa accounting for $94.2 \%$ versus $42.5 \%$ in mothers with abruptio placentae. Placenta accrete found in 14 cases of placenta previa accounting for $7 \%$ of placenta previa and found to be the cause of only one maternal death that occurred in our study which was due to irreversible shock after cesarean hysterectomy. Kedar et al. ${ }^{15}$ study reported only one placenta accrete in placenta previa group of his study (2.5\%) and only one maternal death, but what differentiated it from our study is that the maternal death was due to shock and renal failure of a lady presented as severe abruption placentae. Blood transfusion $\geq 5$ units required in 10 cases of placenta previa and 7 cases of abruptio placenta in present study whereas in Majumder et al. ${ }^{12}$ study $\geq 5$ units of blood were given in 3 cases of placenta previa and 2 cases of abruption placenta. This may be due to their small sample size and the higher incidence of anemia in our study. The perinatal mortality in our study was $23.64 \%$ which was parallel to the study done by Wasnik et al. ${ }^{13}$ which was $21 \%$ and Adekanle et al. ${ }^{21}(22.2 \%)$. Meanwhile, we found high low birth weight rate in the current study, which was $50.7 \%$ for abruption placentae, and $34.3 \%$ for placenta previa, but these were $67.64 \%$ and $33.34 \%$ respectively in Kedar et al. ${ }^{15}$ study. We observed that $68.6 \%$ of perinatal deaths were $<34$ weeks gestation, and this explains that prematurity was a major cause behind most admissions to the nursery and perinatal mortality. Furthermore, perinatal death in our study had a statistically significant association with fetal weight at delivery. The perinatal death was $44.57 \%$ in babies $<1.5 \mathrm{~kg}$ and $50.6 \%$ in babies weighing $1.5-2.5 \mathrm{Kg}$. it also showed that the rate of stillbirth babies was high even in babies weighing $>2.5 \mathrm{~kg}$
$(75 \%)$, while early neonatal deaths decrease with increasing weight $>2.5 \mathrm{~kg}$ $(25 \%)$, and these were consistent with Shavita Jain et al. study. ${ }^{22}$ Type of APH and mode of delivery also found to have an effect on perinatal death in the present study, overall PNM in abruption $36.3 \%$ was higher than placenta previa $17.4 \%$, which was consistent with Arora et al. ${ }^{19}$ and Shavita Jain et al. study. ${ }^{22}$ It is worthy to mention that Stillbirth babies in vaginal deliveries was $90 \%$ in compared to those delivered by cesarean section $26.9 \%$, and this was consistent with Singh et al. ${ }^{17}$ which found that perinatal mortality is much higher in vaginal deliveries compared to cesarean section in abruption placenta. Mothers who presented with shock were 9.6 times more likely to have perinatal death than mothers without shock. We did not find such association reported before in other studies, but we found male predominance in perinatal death in the current study, $61.4 \%$ of perinatal deaths were male in compared to $38.55 \%$ were female, which was identical to Shavita Jain et al. study. ${ }^{22}$

\section{Conclusion}

$\mathrm{APH}$ is still regarded one of the major causes of maternal and perinatal mortality and morbidity. On the one hand, the scarred uterus was found to be the main risk factor for placenta previa and accrete, which further increased the rate of cesarean section and cesarean hysterectomy. On the other hand, preeclampsia, and previous APH increased the risk of abruptio placentae. Maternal presentation with shock and low birth weight babies significantly associated with increased perinatal mortality, while birth weight $>2.5 \mathrm{~kg}$ and cesarean mode of delivery significantly reduced perinatal mortality.

\section{Competing interests}

The author declares no competing interests. 


\section{References}

1. Konje JE, Taylor DJ. Bleeding in late pregnancy. In In James DK, Steer PJ, Weiner CP, Gonik B, editors. High risk pregnancy management options. 2nd ed. London: HartCourt; 2010.

2. Cantwell R, Clutton-Brock T, Cooper G, Dawson A, Drife J, Garrod D, et al. Saving Mothers' Lives: reviewing maternal deaths to make motherhood safer: 2006--08. The Eighth Report on Confidential Enquiries into Maternal Deaths in the United Kingdom. BJOG 2011;118 (Suppl. 1): 1-203.

3. Department of Health. Saving mothers 2005-2007: fourth report on confidential enquiries into maternal deaths in South Africa; Pretoria: Department of Health; 2009.

4. Royal College of Obstetricians and Gynaecologists. Antepartum Haemorrhage; Green-top Guideline No. 63; 2011.

5. Dutta DC. Antepartum hemorrhage. In text book of obstetrics. 6thed. Kolkatta: New central book agency; 2006. P. 243-6.

6. Seema B. Risk factors and clinical outcome of placental abruption: a retrospective analysis. J Pak Med Assoc 2009; 22:20.

7. Babikir DA. Risk factors predisposing to abruptio placentae. Maternal and fetal outcome. Saudi Med J 2004; 25(9):1237-40.

8. Minna T. Etiology, clinical manifestations, and prediction of placental abruption. Acta Obstet Gynecol Scand Suppl 2010; 89(6):732-40.

9. Sinha P, Kuruba N. Antepartum haemorrhage: an update. J Obstet Gynaecol 2008; 28(4):377-81.

10. Walfish M, Neuman A, Wlody D. Maternal haemorrhage. $\mathrm{Br} J$ Anaesth 2009; 103(suppl 1):i47-56.

11. Lawn JE, Lee AC, Kinney M, Sibley L, Carlo WA, Paul VK, et al. Two million intrapartum-related stillbirths and neonatal deaths: where, why, and what can be done? Suppl Int J Gynecol Obstet 2009; 107(Suppl 1):S5-18.

12. Siddhartha M, Shah PT, Deliwala KJ, Patel RV, Madiya A. Study of foetomaternal outcome of antepartum haemorrhage in pregnancy. Int J Reprod Contracept Obstet Gynecol 2015; 4(6):1936-9.

13. Wasnik SK, Naiknaware SV. Antepartum haemorrhage: Causes and its effects on mother and child: An evaluation. Obstet Gynecol Int J 2015; 3(1):00072.

14. Ayushma, Jejani and Anjali, Kawthalkar. Study of obstetric outcome in antepartum haemorrhage. Panacea J Med Sci 2015; 5(3):153-7.

15. Kedar K, Uikey $P$, Pawar A, Choudhary A. Maternal and fetal outcome in antepartum haemorrhage: a study at tertiary care hospital. Int J Reprod Contracept Obstet Gynecol 2016; 5(5): 1386-91.

16. Archana M, Sonal A. Study of antepartum haemorrhage and its maternal and perinatal outcome. IJSRP 2014; 4(2):1-8.
17. Singh AG, Ghanghoriya V and Chauhan R. Maternal and fetal outcome in abruptio placentae at nscb medical college hospital Jabalpur, India. EJBPS 2015; 2(3):1446-52.

18. Singhal S, Nanda NS. Maternal and perinatal outcome in antepartum haemorrhage: A study at a tertiary care referral institute. Internet $\mathrm{J}$ Gynecol Obstet 2008; 9(2):5580.

19. Arora R, Devi U, Majumdar K. Perinatal morbidity and mortality in antepartum haemorrhage. J Obstet Gynaecol India 2001; 51(3):102-4.

20. Nega C, Hailemariam S, Kiflie AY. Incidence, Contributing Factors and Outcomes of Antepartum Hemorrhage in Jimma University Specialized Hospital, Southwest Ethiopia. Univers J Public Health 2015; 3(4):153-9.

21. Adekanle DA, Adeyemi AS, Fadero FF. Ante-partum haemorrhage and pregnancy outcome in Lautech teaching Hospital, southwestern Nigeria. J Med Sci 2011; 2(12): 1243-7.

22. Shaveta J, Nitin J, Pushpa D, Seema R, Roopa $M$. Perinatal outcome in antepartum hemorrhage in teaching hospital of northern India: A prospective study. IJSRP 2015; 5(2):1-6. 